\title{
Sensorless Control of Brushless DC Motors based on TMS320F2812
}

\author{
Ziyu Wu *, Haifeng Wang **
}

\begin{abstract}
A new sensorless control strategy for brushless DC (BLDC) motors is proposed in this paper. This technique builds a rotor position-related flux function, which is independent of the speed. By observing the flux function, the information of rotor position and commutation can be obtained. As the function is not speed-related, this control process can be used in a wider range of speed and improves the motor's performance during startup. An experimental test bad based on TMS320F2812 has been built, and the experimental result indicates that the motor achieves a smooth starting-up and stable phase commutation with the proposed control strategy.
\end{abstract}

Keywords: Sensorless control, BLDC, Flux function, TMS320F2812

\section{Introduction}

By adopting power electronic switches to realize commutation, the brushless DC (BLDC) motors can decreases noise of the motor and prolong the life of equipment. At the same time, its high torque and easy control can compare with the DC motor [1-3]. But BLDC motor requires rotor position sensors to acquire proper commutation of current, and hall-sensor will increase the volume and cost of the motor. Also, hall-sensors cannot work in high temperature or high humidity environment [46]. Thus limits the application of the BLDC motor. Hence, the sensorless control of the BLDC motor technique becomes a hot research field recently.

The most popular sensorless control category is based on detecting the back electromotive force (EMF). For typical operation of a BLDC motor, the phase current and backEMF should be aligned to obtain maximum torque. And the ideal commutation point is 30 electrical degree shift the zero-crossing point (ZCP) of the non-excited phase backEMF. There are many methods based on this idea [7], including detecting back-EMF directly, back-EMF integration, building back-EMF observers like Kalman observer [8] or sliding-mode observer [9] and so on [10, 11]. However, most of these methods work well only in a narrow range of speed as the amplitude of Back-EMF is related to speed. Besides, detecting the third harmonic

\footnotetext{
Institute of Electrical Engineering, Chinese Academy of sciences, China. (wuzy@mail.iee.ac.cn)

** Institute of Electrical Engineering, Chinese Academy of sciences, China. (wanghf@mail.iee.ac.cn)

Received 11 October 2013; Accepted 28 November 2013
}

component of phase voltage [12] or the freewheeling diodes conduction is also researched. But these method need extra complex hardware.

This paper introduces a novel sensorless control method by building a flux function that is not speed-related [13]. Because the function is not related to speed, it can work well in a wider range of speed. To evaluate the performance of the proposed flux function method, a Simulink model in Matlab/Simulink and a test bed have been built.

\section{Calculation of Flux Function}

\subsection{Mathematical model of a BLDC motor}

The back-EMF of a BLDC motor is trapezoidal, and only two phases are activated for every 60 electrical degree. The equivalent circuit of BLDC motor with driver is shown in Fig.1.

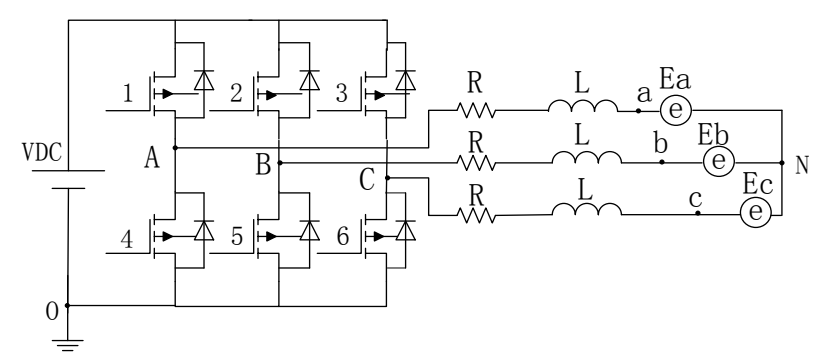

Fig. 1. Equivalent circuit of a BLDC motor and inverter

From Fig.1, the voltage equation of a BLDC motor can be described as in (1). 
$\left[\begin{array}{l}V_{a} \\ V_{b} \\ V_{c}\end{array}\right]=\left[\begin{array}{lll}R & 0 & 0 \\ 0 & R & 0 \\ 0 & 0 & R\end{array}\right]\left[\begin{array}{l}i_{a} \\ i_{b} \\ i_{c}\end{array}\right]+\left[\begin{array}{ccc}L & 0 & 0 \\ 0 & L & 0 \\ 0 & 0 & L\end{array}\right] \frac{d}{d t}\left[\begin{array}{c}i_{a} \\ i_{b} \\ i_{c}\end{array}\right]+\left[\begin{array}{c}e_{a} \\ e_{b} \\ e_{c}\end{array}\right](1)$

According to the mathematic model of BLDC motor as shown in (1), the line-line voltage equation can be represented as in (2).

$$
U_{a b}=\left(R i_{a}-i_{b}\right)+L \frac{d\left(i_{a}-i_{b}\right)}{d t}+k_{e} \frac{d \theta}{d t} \frac{d\left(f_{a b r}(\theta)\right)}{d \theta}
$$

Where, Uab, ia, ib, L, fabr $(\theta)$ represent the line voltage between phase $\mathrm{A}$ and $\mathrm{B}$, the current of phase $\mathrm{A}$, the current of phase $\mathrm{B}$, the phase inductance under balanced condition, and a line-to-line flux linkage form function that is related to the rotor position.

From (2), a function can be defined as in (3).

$$
H(\theta)_{a b}=\frac{d f_{a b r}(\theta)}{d \theta}=\frac{1}{\omega \sqsubset k_{e}}\left[\left(V_{a}-V_{b}\right)-R\left(i_{a}-i_{b}\right)-L \frac{d\left(i_{a}-i_{b}\right)}{d t}\right]
$$

In order to decoupling from the speed term, one $\mathrm{H}$ function is divided by another. Thus, a new function can be defined as

$$
G(\theta)_{a b / c a}=\frac{H(\theta)_{a b}}{H(\theta)_{c a}}=\frac{U_{a b}-R i_{a b}-L \frac{d i_{a b}}{d t}}{U_{c a}-R i_{c a}-L \frac{d i_{c a}}{d t}}
$$

The $\mathrm{G}$ function in (4) has the high sensitivity at the commutation moment, and it is not related to the speed. According to calculating $G$ function, the commutation signal can be obtained.

\subsection{Principle of the proposed sensorless control algorithm}

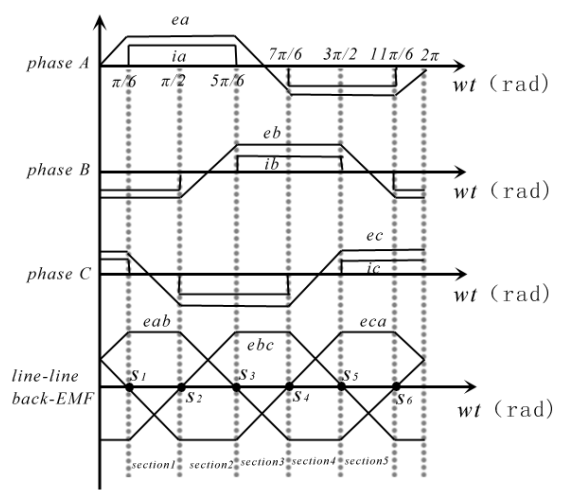

Fig. 2. Back-EMF and current waveform of BLDCM
In the 120 degree conduction model, there are only two of three phases conducting at one time of BLDC motor. The ideal back-EMF and current waveform of a BLDC motor is shown in Fig.2. From Fig.2, the exact commutation points $(\mathrm{S} 1 \sim \mathrm{S} 6)$ are $30^{\circ} \mathrm{E}$ delay from ZCP of phase back-EMF, and are the exact zero cross points of line-line back-EMF. In fact, the $\mathrm{G}$ function is the division of two line-line backEMF as shown in (5).

$$
G(\theta)_{a b / c a}=\frac{H(\theta)_{a b}}{H(\theta)_{c a}}=\frac{U_{a b}-R i_{a b}-L \frac{d i_{a b}}{d t}}{U_{c a}-R i_{c a}-L \frac{d i_{c a}}{d t}}
$$

Since the current is steady before the moment of commutation, the voltage drop of induction which caused by the change of the current can be ignored. Then (5) can be descried as

$$
G(\theta)_{a b / c a}=\frac{U_{a b}-R i_{a b}-L \frac{d i_{a b}}{d t}}{U_{c a}-R i_{c a}-L \frac{d i_{c a}}{d t}} \approx \frac{U_{a b}-R i_{a b}}{U_{c a}-R i_{c a}}
$$

When the rotor moves to the commutation point, the denominator of (6) is at zero crossing point and numerator of (6) reaches maximizing. Then the value of $G$ function reaches maximizing at commutation points. By comparing $\mathrm{G}$ with a threshold constant, the commutation signal can be got. Since there are six switch status in every electrical period, in order to get commutation point at each section, different $G$ functions are calculated. Then the whole commutation signal can be get.

Table 1. Different G function in every status

\begin{tabular}{|c|c|}
\hline Status 1 and 4 & $G(\theta)_{c a l b c}=\frac{U_{c a}-R i_{c a}}{U_{b c}-R i_{b c}}$ \\
\hline Status 2 and 5 & $G(\theta)_{b c / a b}=\frac{U_{b c}-R i_{b c}}{U_{a b}-R i_{a b}}$ \\
\hline Status 3 and 6 & $G(\theta)_{a b l c a}=\frac{U_{a b}-R i_{a b}}{U_{c a}-R i_{c a}}$ \\
\hline
\end{tabular}

\section{Sensorless Control Strategy}

When the BLDC motor starts up, in order to know which switches should be conducted, the initial rotor position need to be known. To solve the startup problem, sensorless control strategy of BLDC motor include three steps, preposition section, the voltage and frequency boost section and the $\mathrm{G}$ function control section. When the motor is static, 
the pre-position section active two phases and wait for enough time. If the initial rotor position is not at the desired position, the active phases generate forcing torque to cause rotor shaft to rotate and lock at the desired position. After the rotor locking at the desired position, the voltage and frequency boost section give commutation signal to make the motor speed up to a desired speed. Once the motor reaches the desired speed, and the back-EMF can be calculate exactly, the $\mathrm{G}$ function section begin to work and give the commutation signal.

The whole sensorless control strategy schema diagram is shown in Fig.3

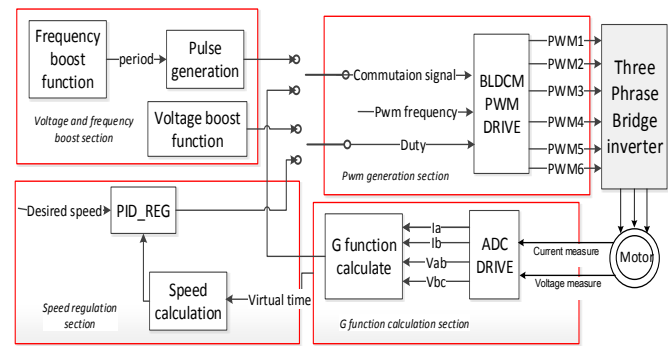

Fig. 3. The schematic of sensorless control strategy

To realize the sensorless control strategy, the schematic diagram consists of four parts, the voltage and frequency boost section, the PWM generation section, the speed regulation section and the $G$ function calculation section. The voltage and frequency boost section gives commutation and duty signal to PWM generation section when the motor startup, then the PWM generation section gives PWM signal to inverter and conduct switches to drive motor startup. After startup the $G$ function calculation section collecting the current and voltage information of the motor and calculate the flux function and give commutation signal to PWM generation section. Thus, the motor can work without rotor sensors.

\section{Simulation and Experimental Results}

Table. 2. Parameters of the BLDC motor

\begin{tabular}{|l|l|l|l|}
\hline Rated voltage & $310(\mathrm{~V})$ & Rated current & $5.4(\mathrm{~A})$ \\
\hline Rated torque & $6(\mathrm{~N} \cdot \mathrm{m})$ & $\begin{array}{l}\text { Stator } \\
\text { Resistance }\end{array}$ & $1.43(\Omega)$ \\
\hline Rated speed & $2000 \mathrm{rpm}$ & $\begin{array}{l}\text { Stator } \\
\text { inductance }\end{array}$ & $4.21(\mathrm{mH})$ \\
\hline Rated power & $1200(\mathrm{w})$ & Poles & 8 \\
\hline
\end{tabular}

In order to test the performance of the presented sensorless control strategy, both a simulation model in Matlab/Simulink and an experiment test bed are built. The experiment test bed is consist of a BLDC motor, inverter and a TMS320F2812 digital signal processor. The parameters of the BLDC motor is shown in table.2.

\subsection{Simulation Results}

In simulation, assuming the initial rotor position is at 0 degree, and the motor can startups directly. Once the rotor moves, $\mathrm{G}$ function is calculated. When $\mathrm{G}$ function exceeded the threshold, the switches status change and the current commutation.

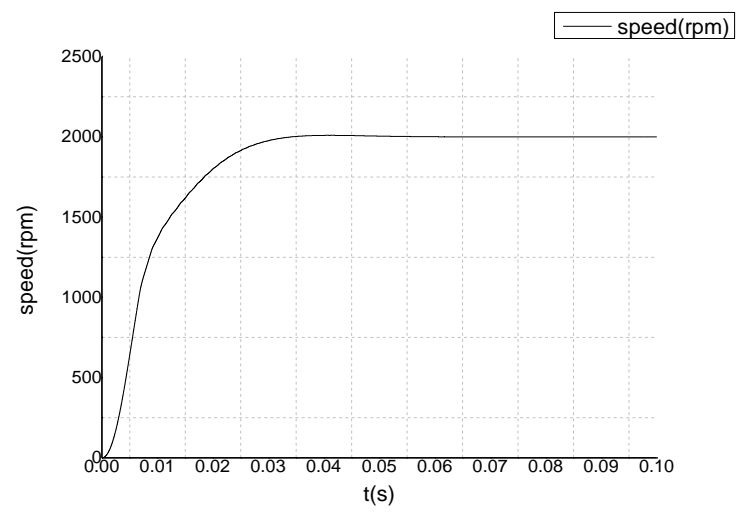

(a)

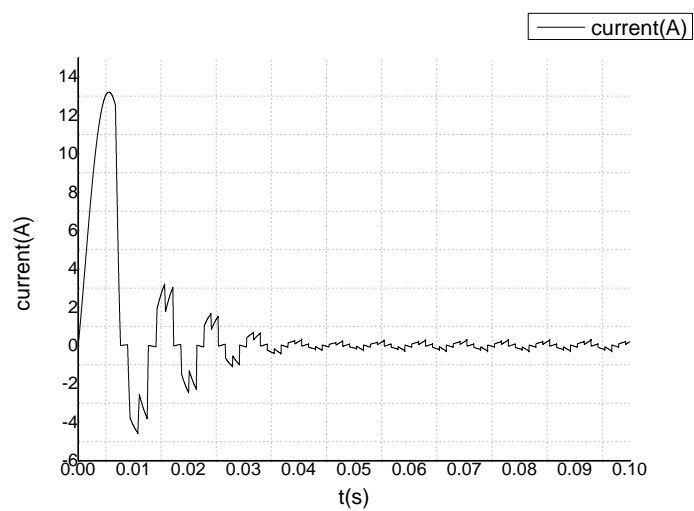

(b)

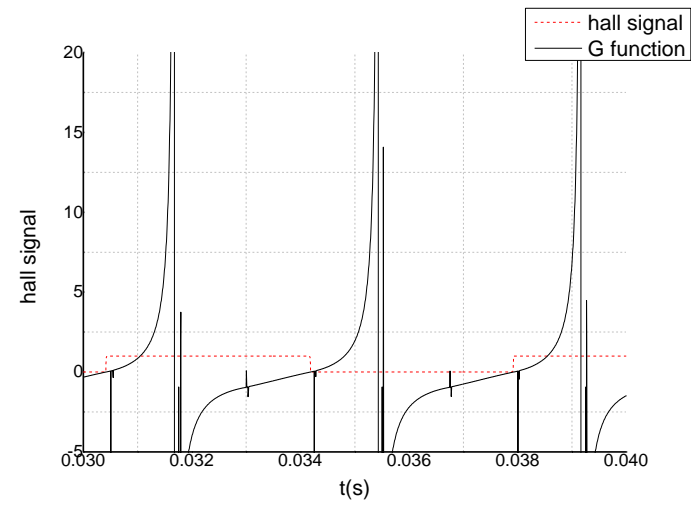

(c)

Fig. 4. Sensorless performance in Simulink of the motor start with non-loaded (a) rotor speed. (b) Phase current. (c) Comparison of the $\mathrm{G}$ function and actual hall position during startup. 
Fig 4 shows the performance of the motor startups with unloaded. Fig.4 (a) shows the speed responds when the reference speed set as 2000rpm. (b) shows the current response. The maximum current during startup is $17 \mathrm{~A}$, and when speed is steady, the current decreases nearly zero. (c) shows the comparison between $\mathrm{G}$ function and hall signal. It can be seen that the $G$ function reaches great value at commutation position, and even when the speed varies, $G$ function can still follow up with hall signal.

Fig.5 shows the performance of the motor under sensorless control with rated load. From (a), the motor can startup in short time and smoothly. The maximum current during startup is $25 \mathrm{~A}$. After startup, the current stabilizes at rated value. (c) shows the comparison between $\mathrm{G}$ function and hall signal. When the motor with rated load, the $G$ function can follow up with hall position well.

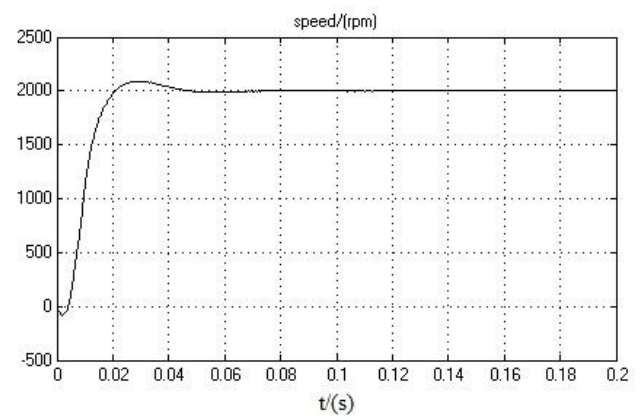

(a)

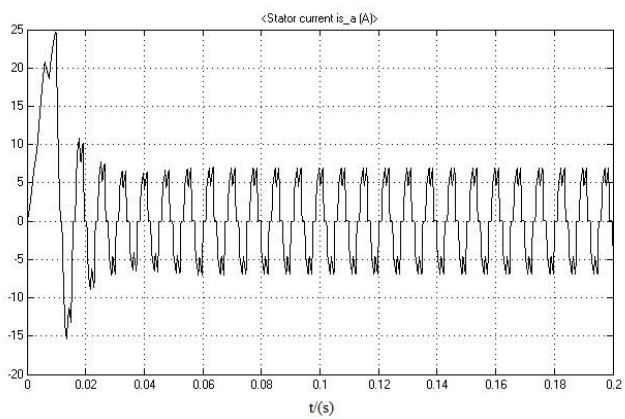

(b)

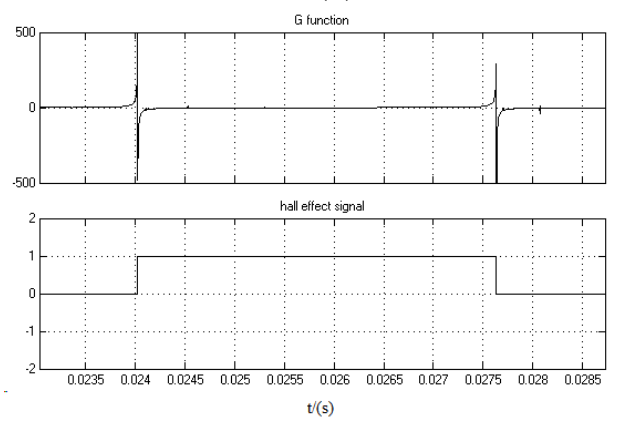

(c)

Fig. 5. Sensorless performance in Simulink of the motor start with rated-loaded (a) rotor speed. (b) Phase current. (c) Comparison of the $G$ function and actual hall position during startup.

\subsection{Experimental Results}

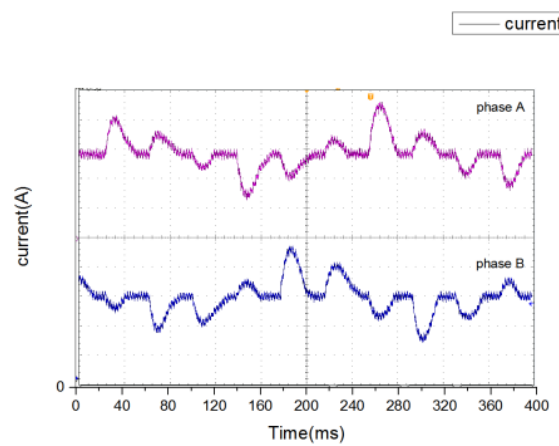

(a)

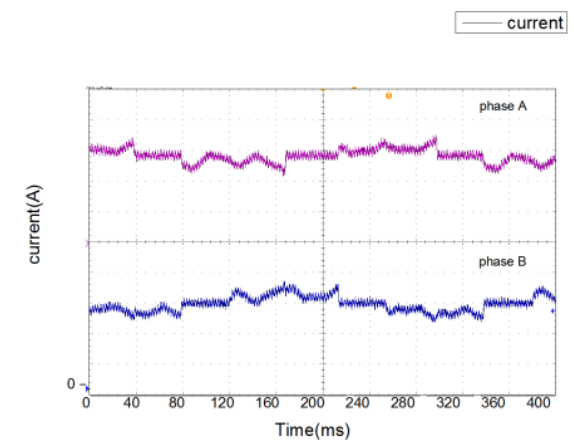

(b)

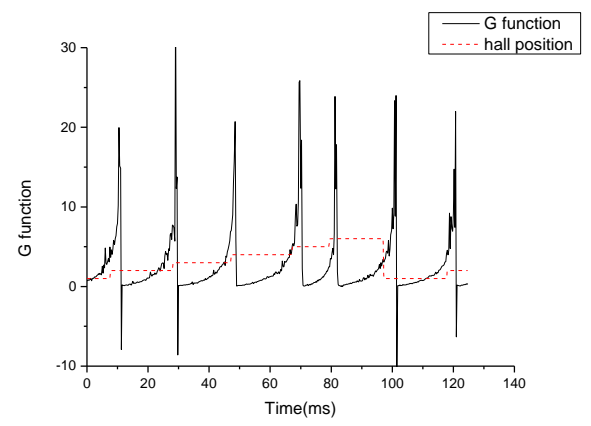

(c)

Fig. 6. Current and $G$ function waveform when motor startup with non-loaded. (a) Open-loop current. (b) Closed-loop current. (c) Comparison between hall position and $\mathrm{G}$ function

As there is no measurement noisy in Simulink model, the back-EMF can be calculated accurately. And the performance of the algorithm in Simulink is quite excellent. But there is much noisy in reality, to test the performance of the control algorithm in real environment, a test bed is built.

In the experiment test bed, the performance of the proposed sensorless control strategy has been tested. The whole test bed consists of a $1.2 \mathrm{kw}$ motor with driver, a TMS320F2812 digital signal processor. When motor is starting, the pre-position function locks the rotor at the desired position. Then the voltage and frequency boost 
function speed up the motor to desired speed. By changing the parameter of voltage and frequency boost function, the desired speed can be modified. However, during the speed up stage, the motor works under open loop control, and easily lose balance and fail to startup. Hence, the $G$ function should obtain the exact commutation signal at low speed, which will decrease the open loop time and improve the start-up performance. The current and voltage are measured by measurement circus. The digital signal process sampling the measurement signal and calculate the $G$ function at $40 \mathrm{kHz}$.

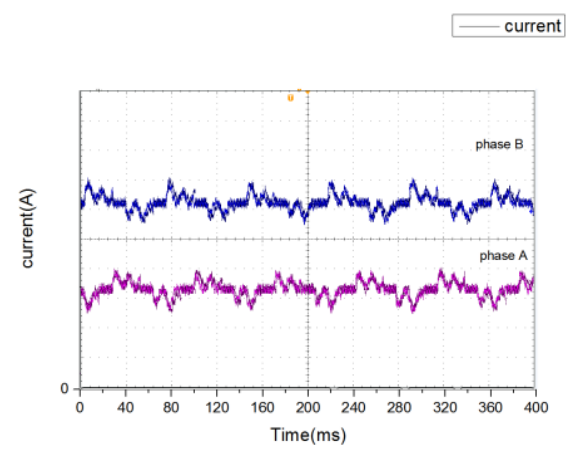

(a)

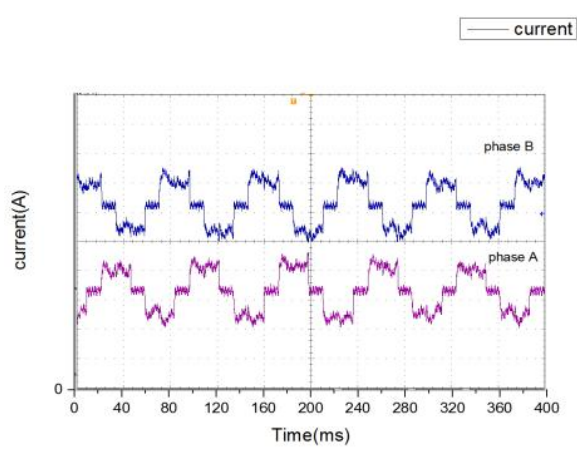

(b)

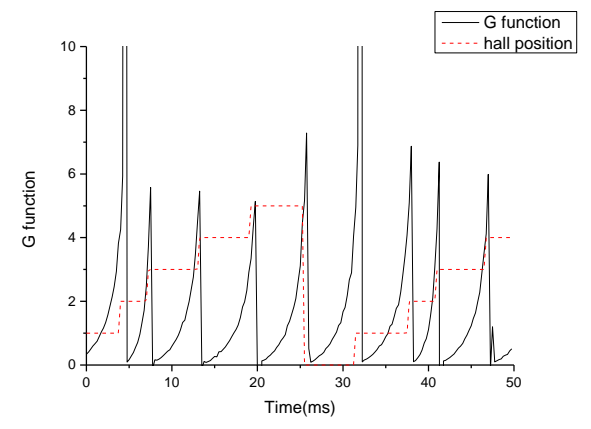

(c)

Fig. 7. Current waveform and $\mathrm{G}$ function waveform at 400r/min (a) Current waveform with non-loaded. (b) Current waveform with 1N.m loaded. (c) Comparison between $\mathrm{G}$ function and hall position with loaded.

Fig.6 shows the current and $\mathrm{G}$ function waveform during the startup stage. In Fig.6 (a) and (b), one grid represent 1A.
The final DC voltage of the open-loop stage is $13.8 \mathrm{v}$ and rotation speed reaches at $127 \mathrm{r} / \mathrm{min}$. After switching to closed-loop, the speed becomes near 121r/min. By comparing (a) and (b), it can be found that the current is much bigger at open-loop than at closed-loop. It indicates that the motor has big commutation angel error during the open-loop, which is disadvantage for motor to startup. But the current is nearly zero after changing to closed-loop. Fig.6 (c) shows the comparison between $G$ function and hall signal. It indicates the $\mathrm{G}$ function can track the rotor position agilely. From Fig.6, it can be seen that the sensorless algorithm has excellent performance even when the speed is very low.

After start-up, the motor speed up under sensorless control. Fig.7 (a) and (b) shows the current waveform of non-loaded and loaded at $400 \mathrm{r} / \mathrm{min}$. (c) shows the comparison of $\mathrm{G}$ function and hall position with loaded. When the motor speed ups and with loaded, the current is steady and $G$ function still follows up with real rotor position. It indicates the sensorless algorithm works well with loaded.

\section{Conclusion}

This article proposed a novel sensorless control method of BLDC motor based on flux function estimation. The flux function can be estimated by line-line voltage without building up a neutral point. The flux function follows up the rotor position agilely and is not speed-related. Under this method, the commutation point can be detected accurately even at low speed (above 120r/min), which improves the startup performance of BLDC motor sensorless control. Also, the sensorless method works well when the motor with light load.

\section{Acknowledgements}

This work was supported by the project of National Natural Science Foundation, the name of which is Research the Mechanism of the Inner Evaporative Cooling System with Small Inclination in Direct-Driven Wind Turbine Generators (51177157).

\section{References}

[1] A. Tashakori and M. Ektesabi, "Stability Analysis of Sensorless BLDC Motor Drive U sing Digital PWM Technique for Electric Vehicles," 38th Annual Conference on Ieee Industrial Electronics Society (Iecon 2012), pp. 48984903, 2012. 
[2] Y. L. Gao and Y. L. Liu, "Research of Sensorless controller of BLDC Motor," 2012 10th Ieee International Conference on Industrial Informatics (Indin), pp. 725-728, 2012.

[3] P. Kshirsagar and R. Krishnan, "High-Efficiency Current Excitation Strategy for Variable-Speed Nonsinusoidal BackEMF PMSM Machines," Ieee Transactions on Industry Applications, vol. 48, pp. 1875-1889, Nov-Dec 2012.

[4] X. Z. Zhang and Y. N. Wang, "A novel position-sensorless control method for brushless DC motors," Energy Conversion and Management, vol. 52, pp. 1669-1676, Mar 2011.

[5] M. R. Rahmati and M. Jafarboland, "Improving Sensorless Control of BLDC Motors by Offering a New Parameters Estimation Algorithm for BLDC Motors," International Review of Electrical Engineering-Iree, vol. 6, pp. 698-705, Mar-Apr 2011

[6] M. F. Hsieh and H. J. Liao, "A Wide Speed Range Sensorless Control Technique of Brushless Dc Motors for Electric Propulsors," Journal of Marine Science and TechnologyTaiwan, vol. 18, pp. 735-745, Oct 2010.

[7] M. Tawadros, J. Rizk, and M. Nagrial, "Sensor less Control of Brush less Drives Using Back emf Mapping," Second International Conference on Computer and Electrical Engineering, Vol 1, Proceedings, pp. 135-138, 2009.

[8] S. A. K. M. Niapour, M. Tabarraie, and M. R. Feyzi, "Design and analysis of speed-sensorless robust stochastic L-infinityinduced observer for high-performance brushless DC motor drives with diminished torque ripple," Energy Conversion and Management, vol. 64, pp. 482-498, Dec 2012.

[9] F. Hicham, E. Mohamed, R. Abdellatif, and B. Pierre, "Sliding mode observer for position and speed estimations in brushless DC motor (BLDCM)," 2004 Ieee International Conference on Industrial Technology (Icit), Vols. 1- 3, pp. 121-126, 2004.

[10] Z. Lin-sen, X. Shun-yi, Y. Cheng-yu, and Y. Ying-hua, "Position Sensorless Control for Brushless DC Motor Based on RBFNN Optimized by Fast Recurvise Algorithm," pp. 7578, 2009.

[11] R. Kumar, N. Singh, J. Singh, and S. V. Padmanaban, "A nonlinear reduced order observer for rotor position estimation of sensorless permanent magnet brushless DC motor drive," Iecon 2006 - 32nd Annual Conference on Ieee Industrial Electronics, Vols 1-11, pp. 1281-1286, 2006.

[12] Y. H. Yoon, T. W. Lee, S. H. Park, B. K. Lee, and C. Y. Won, "New approach to rotor position detection and precision speed control of the BLDC motor," Iecon 2006 - 32nd Annual Conference on Ieee Industrial Electronics, Vols 1-11, pp. 3364-3369, 2006.

[13] T. H. Kim, B. K. Lee, and M. Ehsani, "Sensorless control of the BLDC motors from near zero to high speed," Apec 2003: Eighteenth Annual Ieee Applied Power Electronics Conference and Exposition, Vols 1 and 2, pp. 306-312, 2003.

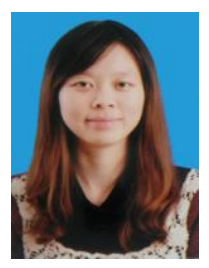

Ziyu Wu received B.S degree in electrical engineering from Wuhan University. Her research interests are emerging energy systems and electric machines.

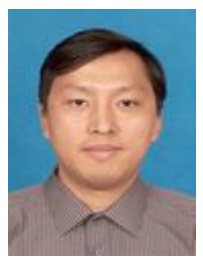

Haifeng Wang received a doctor degree in electrical engineering from Northwestern Polytechnical University. His research interests are emerging energy systems and special motor. 